\title{
Designer Drugs on the Internet: a Phenomenon Out-of-Control? The Emergence of
}

Hallucinogenic Drug Bromo-Dragonfly

ORNELLA CORAZZA ${ }^{1,2}$, FABRIZIO SCHIFANO $^{1}$, MAGI FARRE $^{3}$, PAOLO $^{2}$

DELUCA $^{2}$, ZOE DAVEY $^{2}$, MARTA TORRENS ${ }^{3}$, ZSOLT DEMETROVICS $^{4}$, LUCIA $^{2}$

DI FURIA ${ }^{5}$, LIV FLESLAND ${ }^{6}$, HOLGER SIEMANN $^{7}$, ARVID SKUTLE ${ }^{6}$, PEER VAN

DER KREEFT $^{8}$, NORBERT SCHERBAUM ${ }^{7}$

1 'ReDNet' Project; School of Pharmacy, University of Hertfordshire, Hatfield, UK

${ }^{2}$ National Addiction Centre, Institute of Psychiatry, King's College London, UK

${ }^{3}$ IAPS-IMIM-Hospital del Mar-UAB, Barcelona, Spain

${ }^{4}$ Institutional Group on Addiction, Eötvös Loránd University, Hungary

${ }^{5}$ Servizio Salute Regione Marche, Ancona, Italy

${ }^{6}$ Bergen Clinics Foundation, Centre of Competence, Bergen, Norway

${ }^{7}$ Addiction Research Group at the Department of Psychiatry and Psychotherapy, LVR-

Hospital Essen, Hospital of the University Duisburg-Essen, Germany

${ }^{8}$ De Sleutel Technische Bedrijfseen heid Provincialaat der Broeders van Liefde, Merelbeke, Gent, Belgium

on behalf of the ReDNet Research Group

\section{Corresponding Author:}

Dr Ornella Corazza

Research Manager

Recreational Drugs European Network

University of Hertfordshire

School of Pharmacy

College Lane Campus

Hatfield, Herts

AL10 9AB (UK)

Telephone: +44 (0)1707-289431

Fax: +44 (0)1707-284506

Mobile: +44 (0)7872417798

E-mail: o.corazza@herts.ac.uk 


\begin{abstract}
Based on the material available in both the scientific literature and on the web, the present paper provides an updated pharmacological, chemical, toxicological and behavioural overview of Bromo-Dragonfly (1-(8-bromobenzo[1,2-b;4,5- $b$ ']difuran-4-yl)2-aminopropane; 'B-fly'). B-Fly is a powerful, long lasting, LSD-like, hallucinogenic drug, which has been associated with a number of acute intoxications and fatalities in a number of countries. A critical discussion of the potential of misuse of B-fly but also of the methodological limitations, which are intrinsically associated with the analysis of online, non-peer reviewed, material, is presented. It is concluded that the availability of online information on novel psychoactive drugs, such as B-fly, may constitute a public health challenge. Better international collaboration levels may be needed to tackle this novel and fast growing phenomenon.
\end{abstract}

\title{
Key words
}

ABDF, Bromo-Dragonfly, FLY-compounds, Internet monitoring, phenethylamines, Psychonaut project, ReDNet project, research chemicals 


\section{Introduction}

A new generation of psychoactive drugs related to the phenethylamines' group, known as the 'FLY' drugs, emerged in the last few years as a new recreational drug misuse trend. The most common FLY compounds are:

- 2C-B-FLY: 1-(8-Bromo-2,3,6,7-tetrahydrobenzo[1,2-b;4,5-b']difuran-4-yl)-2aminoethane hydrochloride

- 3C-B-FLY: 1-(8-bromo-2,3,6,7-tetrahydrobenzo[1,2-b;4,5-b']difuran-4-yl)-2aminopropane hydrochloride

- Bromo-Dragonfly: 1-(8-bromobenzo[1,2-b;4,5-b']difuran-4-yl)-2-aminopropane

They are called 'FLY' because their molecular structure resembles the insect: the body of the fly will be the benzene ring; the two wings are the furan or dihydrofuran rings; the head is the bromine atom and the tail is the isopropylamine [1].

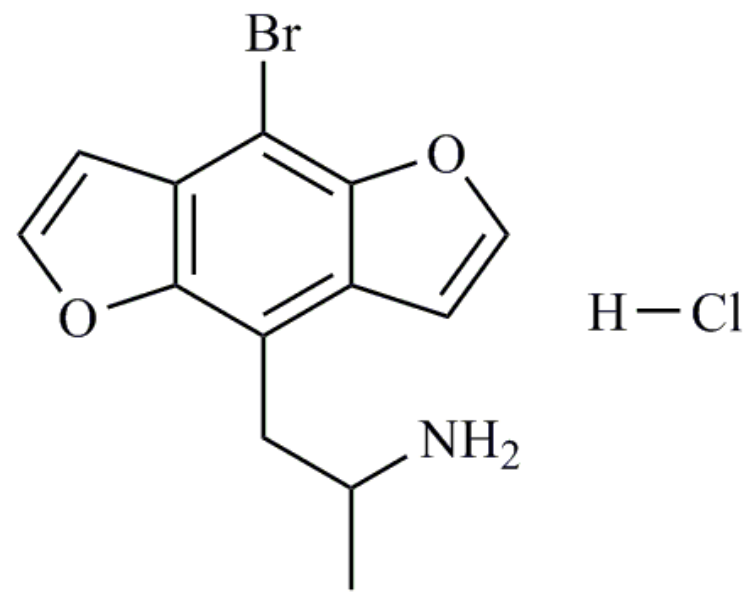

Figure 1

1-(8-bromobenzo[1,2- $b$;4,5- $b$ ']difuran-4-yl)-2-aminopropane hydrochloride (Bromo-Dragonfly) 
In particular, Bromo-Dragonfly was first synthesized by Matthew A. Parker at Purdue University in 1998 and used as a novel brain research chemical with rats [2-5]. Although structurally and chemically it is related to phenethylamines, the phenyl ring of this molecule is bound between two dihydrofuran rings, giving it more potency and much longer duration of action than most other phenethylamines [6]. Its effects can last up to 13 days [1]. A procedure based on liquid chromatography-mass spectrometry (LC-MS) has been described to identify a number of phenethylamines [7], including some of the 'FLY' drugs such as 2C-B-Fly, in the urines of consumers using 3,4 methylendioxypropylamphetamine (MDPA) as internal standard. Its mechanism of action is mediated primarily by agonist activity at the serotonin 5-HT2A receptors as well as to some degree at 5-HT1 receptor [2,8]. It has been speculated that the interaction with both these receptors is likely to be responsible for the hallucinogenic effects [9-11]. Apart from 5-HT2A receptors, there is evidence from both biochemical [12] and behavioural [13-14] studies that the 5-TH2C receptors' subgroups, in both rodents and humans, are involved as well in the pharmacodynamics of B-Fly [13-16].

It has been observed that the synthesis of this substance is complicated by the fact that the molecule can form two distinct chiral or optical isomers and that originally 5 other related synthetic molecules are also called FLY [17]. Although Bromo-Dragonfly is a research chemical and as such not for human consumption, in recent years it has been increasingly abused recreationally. Anecdotal evidence of this epidemic of misuse has emerged from an increased number of fatalities and hospitalizations [18-19], but also from the Internet. Indeed, hundreds of websites advertise the drug for sale and an increasing number of discussions and videos related to the substance are posted online on a regular basis [1023]. B-Fly is currently not legislated for under the UK Misuse of Drugs Act and is legally available in the UK, US and in most of Europe. Conversely, it is a controlled substance in Denmark, Sweden, Norway and Romania.

We aimed at providing here a comprehensive overview of both the peer reviewed and the anecdotal online data on Bromo-Dragonfly. 


\section{Material and Methods}

The literature on Bromo-Dragonfly was searched in three databases, PsychInfo, Pubmed and MedScape. Key words used to carry out the database searches included: '1-(8bromobenzo[1,2-b;4,5-b ']difuran-4-yl)-2-aminopropanehydrochloride', 'BromoDragonfly, 'B-fly' and 'ABDF'. Considering the limitation of peer reviewed, scientific, data results were integrated with a multilingual qualitative assessment of a range of websites, drug-forums and other online resources (e-newsgroups, chatrooms, mailing lists, e-newsletters, and bulletin boards). This was carried out using the Google search engine in 7 languages from a number of collaborating countries (UK, Finland, Norway, Belgium, Germany, Italy and Spain; see http://www.psychonautproject.eu). The online assessment was carried out over the period of one year (February 2009 - 2010) and involved the close monitoring of 203 websites. Of these, 108 were considered to be relevant for the present exercise and as such were monitored on a regular basis i.e., daily $(n=21)$, weekly $(n=32)$, or monthly $(n=53)$, depending on their relevance. The remaining 95 websites were considered not to bear any interest for the present study and thus were no longer monitored. Once the Bromo-Dragonfly was identified on these websites, further specific searches were carried for narratives focusing on the following issues: (a) the nature of its effects on users, including adverse reactions; (b) motivations behind its recreational use and possible trends of misuse, with particular attention to polydrug misuse/idiosyncratic combinations; (c) any other relevant information in the original language of the narratives. The full content of posts/sites of particular interest were also saved and copied onto a dedicated server using a specific programme [24]. This was carried out primarily for historical archiving and for allowing a more thorough and flexible content search using both MacOSX10.6 server built-in search capabilities [25] as well as a third-party search application [26]. Data collected were stored in a passwordprotected online database located within the coordinating centre (St. George's, University of London, UK) and a technical folder with all the available information on the effects of the drug, including various toxicological data, was also created. For the purpose of reporting results in this paper, any data collected from online forums, such as usernames and complete URLs for specific threads that were considered personal identifiable, were 
anonymised. The study was cleared for ethical approval by the Wandsworth Local Research Ethics Committee, London, UK.

\section{Results}

\section{Information on B-Fly online availability, consumption and manufacture}

Although the first reported case of recreational B-Fly abuse can allegedly be traced back to 2001 [23] but, according to Google Insights for Search [27], the web search activity associated with the substance has started to gradually increase only in 2005. BromoDragonfly was then formally identified in 2008 as a new emerging trend of drug abuse during the web monitoring activities of the Psychonaut Web Mapping Project following warnings from a number of EU countries, including Italy, Norway, Belgium, and Finland. 'B-Fly' is typically sold online as blotter papers, liquid and less commonly as pills. According to most online reports, its primary route of administration is oral. After ingestion, the onset of its effects can be delayed for up to 6 hours. This delay has often led recreational users to ingest another dose of the substance thinking that the first dose was inadequate [28]. Alternatively, additional drugs may be ingested while waiting for the psychoactive effects to appear [20, 21, 22, 27, 28]. Although the exact dosage is still unknown, a 'typical' dose is reported by users to be in the region of 200 to $800 \mu \mathrm{g}$ [20]. There are two, or possibly more, types of B-Fly available on the Internet. The first one, called the 'European Batch' (active at dose of 200 to $500 \mu \mathrm{g}$ ) and a less potent one, called the 'American Batch' (active at 800 to $1800 \mu \mathrm{g}$ ) [17]. The average price for $1 \mathrm{gr}$ of Bromo-Dragonfly is about 300 euros/420USD, while a single dose (blotter paper) is around 10-30 euros/14-42USD. Other items such as blotters sheets with various artworks are also widely available online [29].

\section{Effects and adverse reactions}

Some users describe the effects of Bromo-Dragonfly as 'a ride to the moon' because they 'last too long and leave you drained' [20]. Accounts of experiences lasting 2-3 days after the consumption of a single dose (blotter paper) seem to be fairly common [20-21]. Some users report however that B-Fly is 'definitely not for everyone, just too powerful' [21- 
22]. The drug can allegedly induce profound hallucinations (mainly visual distortions, such as geometric patterns and lights), sound alterations, but also other effects such as the sense of connection/belonging with other realities, sense of peace and well-being, emotional stimulation and meeting with entities, which are also common features of the so-called near-death experience [30].

The level of toxicity associated to Bromo-Dragonfly may well be a reason of concern, as recently revealed by a series of hospitalizations and fatalities. For instance, a case of death was recorded in 2008 in a Swedish hospital, where the patient had convulsions, respiratory problems, liver and kidney failure and lost several fingers and toes. This incident was associated with the oral assumption of an allegedly very large amount of BFly $[18,31]$. Another fatality was recorded in Denmark after the ingestion of around $1 \mathrm{ml}$ of 'LSD-like liquid', later identified as Bromo-Dragonfly [32]. The autopsy findings included oedema of the lungs, slight oedema of the brain, enlargement of the spleen, irritation of the mucous membrane in the stomach and ischaemic changes in the kidney [32]. Further fatalities have been recorded in Finland, Denmark, the UK, Norway and the US $[18,19]$. Common adverse reactions may include: nausea and vomiting, headache, tachycardia, elevated blood pressure, lung collapse, gastrointestinal disturbances, muscle tension, tremor, body temperature fluctuations, anxiety, panic attacks, arrhythmias, heart murmurs, slight pupil dilation, convulsions, stomach tightness, hallucinations, flashbacks, memory disturbances, confusion, and paranoid ideation [19, 33].

\section{Motivations for B-Fly intake and polydrug misuse issues}

Most users may approach Bromo-Dragonfly due to its 'psychedelic' properties, which seem to be similar, but of longer duration, to those of lysergic acid diethylamide (LSD) $[20,28,34]$. Other observations are however consistent with the misuser need of enhancing his/her physical sensations (e.g. taste, touch, hearing) and/or to prolong the sexual excitement/pleasure [18]. Other reasons for taking B-Fly have been outlined in Table 1.

Bromo-Dragonfly is often used in combination with a variety of other drugs, generally to enhance or prolong the duration of action of their effects. These polydrug misuse experimentations have led to a range of cases of acute intoxication; particularly worrying 
seems to be the combination of B-Fly with ketamine, with severe agitation, hallucinations and tonic-clonic seizures having been reported $[19,35,36]$.

Table 1: Overview of the alleged reasons for taking B-Fly

\begin{tabular}{|c|c|}
\hline Reasons & Description \\
\hline Hallucinogenic/psychedelic effects & $\begin{array}{l}\text { 'I nearly died from taking a } £ 5 \text { hit', } \\
\text { claimed an 18-year old user, when he was } \\
\text { promised a 'mellow hit, similar to acid but } \\
\text { more enjoyable' [36]. Effects of Bromo- } \\
\text { Dragonfly can include visual distortions, } \\
\text { such as geometric patterns and lights, sense } \\
\text { of belonginglconnecting with other } \\
\text { realities, and sense of unity with the } \\
\text { cosmos among many others [28, 22, 20]. }\end{array}$ \\
\hline $\begin{array}{l}\text { Experimenting with a new substance } \\
\text { and/or with novel combinations }\end{array}$ & $\begin{array}{l}\text { B-Fly is reportedly often taken in } \\
\text { combination with other compounds in order } \\
\text { to try a different 'high' }[23,22,28] \text {, such } \\
\text { as: } \\
\text { - Alcohol } \\
\text { - Prescribing drugs: alprazolam } \\
\text { - Illicit/recreational drugs: } \\
\text { hashish/marijuana; cocaine; } \\
\text { amphetamines; LSD; ketamine } \\
\text { - 'Legal highs', including: Salvia } \\
\text { divinorum; and Kratom (Mytragina } \\
\text { speciosa) }\end{array}$ \\
\hline By mistake & $\begin{array}{l}\text { Large numbers of users have tried B-Fly } \\
\text { thinking it was LSD, especially because } \\
\text { both substances are available in the form of }\end{array}$ \\
\hline
\end{tabular}




\begin{tabular}{|l|l|}
\hline & blotter paper [20, 22]. \\
In 2009 there have been reports of users \\
taking B-Fly by mistake thinking it was \\
'2CB-fly' due to a mislabel batch sold \\
online [22, 36]. \\
'Thankful I am alive', said one these \\
messages posted by a 23-year-old man: \\
'I was in a nearly catatonic state, unable \\
and not wanting to move. Eyes closed the \\
whole time. I couldn't keep them open (...). \\
It was $23^{\circ}$ C outside, yet I was freezing. I \\
was under all of the covers in my bed, yet I \\
began sweating immensely. I couldn't tell if \\
I was awake or sleeping. Conscious or \\
unconscious. It seemed I was somewhere in \\
between the two. This scared me a bit. \\
(After 50 hours) I still don't feel normal. I \\
hope I do soon" [20].
\end{tabular}

\section{Discussion}

The present work provided a review of the current state of knowledge of BromoDragonfly in the peer reviewed literature. To the best of our knowledge, it also provided 
for the first time a critical analysis of the information from and for web surfers/users relating to B-Fly psychoactive effects, adverse reactions and use in combination with other drugs. It seems from here that reasons behind Bromo-Dragonfly increase in popularity include: its powerful a long lasting, LSD-like, hallucinogenic effects; its favourable legal status; and its affordability. Indeed, B-Fly is at times promoted with special offers. Online popularity of B-Fly may have increased as a result of technical facilities such as: 'alerts' about novel psychoactive products via text messages and/or instant messaging; and 'e-mail this product to a friend' [37, 38].

Young/vulnerable individuals might be encouraged by a range of widely available online comments/messages/videos relating to the B-Fly intake experiences. This may be an issue of concern, if one considers that an estimated $61 \%$ of young European people aged between 15-24 years typically quote the Internet as a potential source of information on illicit drugs [39]. Furthermore, it appeared from here that only a minority of drug selling websites were allegedly limiting access to the relevant links to under age individuals.

At the time of writing, B-Fly remains legal in most of the EU countries. This may be an intriguing issue, given its chemical structure similarity with other, already controlled, phenethylamines such as 4-bromo-2,5dimethoxyphenethylamine (2C-B) and 4-bromo2,5-dimethoxyamphetamine (DOB). The current legal status of B-Fly may arguably facilitate the increasing levels of popularity of the drug, but might affect as well the users' perception of risks associated with its consumption. In fact, the idea that legality can equate with safety still remains well grounded amongst some recreational users [37, $40,41]$.

Most of the novel psychoactive compounds available online, such as B-Fly, share a number of characteristics that may constitute a public health challenge, including: (a) not being approved for human consumption; (b) their intake possibly being associated with a number of unknown side effects/adverse reactions); (c) very few related pharmacological/toxicological data being available in the peer reviewed, scientific, literature, with the limited knowledge being mostly restricted to pre-clinical studies; (d) rapidly appearing in always more sophisticated forms and remaining unregulated for a long period of time; (e) being most often synthesized in underground laboratories simply modifying the molecular structure of remaining controlled drugs (e.g. amphetamines; 
tryptamines), hence raising further concerns in terms of presence of contaminating agents; (f) being largely available online and thus 'just a click' away from our homes and potentially available to everyone; (h) being increasingly accepted as part of a 'trendy' lifestyle, because the internet may arguably act as an enabler for niche activities to develop into social norms.

A possible limitation of the present study could be given by the fact that only publicly available websites, forums and similar were monitored. Conversely, to improve the coverage of the study not only the web pages but also more private ways of communication (including newsgroups, chatrooms, mailing lists, newsletters, and bulletin boards) were here considered. A further limitation may be given by the fact that the present findings do rely mostly on what reported by users. In particular, we did not have any possibility here to understand if the substance the online B-Fly misusers were taking was indeed B-Fly.

One could conclude that a constant level of web monitoring activities with respect to drug-related issues is a necessary step to better understand the level of the diffusion of novel psychoactive substances, such as B-Fly. From this point of view, better international collaboration levels may be needed to tackle this novel and fast growing phenomenon. Finally, it is suggested that the use of technological tools could be successfully incorporated in specific prevention programmes for novel compounds in the field of eHealth, as currently piloted by the Recreational Drugs European Network (ReDNet; http://www.rednetproject.eu) [41].

\section{Acknowledgments}

This publication arises from the activities of two studies Psychonaut Web Mapping project and the ReDNet Research Project, which have received funding from the European Union, in the framework of the Public Health Programme (2006 348; 200912 16).

\section{References}


[1] Reed EC, Kiddon GS. The characterization of three FLY compounds (2C-BFLY, 3C-B-FLY, and BromoDragonFLY). DEA Microgram Journal 2007; 5: 4-12.

[2] Parker MA, Marona-Lewicka D, Lucaites VL, Nelson DL, Nichol DE. A novel (benzodifuranyl)aminoalkane with extremely potent activity at the 5-HT2A receptor. J Med Chem 1998; 41: 5148-9.

[3] Monte, AP, Marona-Lewicka D, Parker MA, Wainscott DB, Nelson DL, Nichols DE. Dihydrobenzofuran analogues of hallucinogens. J Med Chem 1996; 39: 2953-61.

[4] Chambers JJ, Kurrasch-Orbaugh DM, Parker MA, Nichols DE. Enantiospecific synthesis and pharmacological evaluation of a series of super-potent, conformationally restricted 5-HT2A/2C receptor antagonists. J Med Chem 2001; 44: 1003-10.

[5] Anonymous. "Bromo-Dragonfly" (bromo-benzodifuranyl-isopropylamine) in Ashland, Oregon. Microgram Bulletin 2007; 40:78.

[6] Shulgin A, Shulgin A. PIHKAL A Chemical Love Story. Transform Press; Berkeley, CA 1998.

[7] Pichini S, Pujadas M, Marchei E, Pellegrini M, Fiz J, Pacifini R, Zuccaro P, Faree' M, de la Torre R. Liquid chromatography-atmospheric pressure ionization electrospray mass spectrometry determination of "hallucinogenic designer drugs" in urine of consumers. J Pharm Biomed Anal 2008; 47: 335-42.

[8] Fiorella D, Rabin RA, Winter JC. The role of the 5-HT2A and 5-HT2C receptors in the stimulus effects of hallucinogenic drugs I: Antagonist correlation analysis. Psychopharmacol 1995; 121: 347-56.

[9] Titeler M, Lyon RA, Glennon RA. Radioligand binding evidence implicates the brain 5-HT2 receptor as a site of action for LSD and phenylisopropylamine hallucinogens. Psychopharmacol 1988; 94: 213-6.

[10] Glennon RA. Do classical hallucinogens act as 5-HT2 agonists or antagonists? Neuropsychopharmacol 1990; 3: 509-17.

[11] European Monitoring Centre for Drugs and Drug Addiction: Report on the risk assessment of 2C-I, 2C-T-2 and 2C-T-7 in the framework of the joint action on 
new synthetic drugs. Office for Official Publications of the European Communities, Luxembourg 2004.

[12] Sanders-Bush E, Burris KD, Knoth K. Lysergic acid diethylamide and 2,5dimethoxy-4-methylamphetamine are partial agonists at serotonin receptors linked to phosphoinositide hydrolysis. J Pharmacol Exp Ther1988; 246: 924-8.

[13] Marek GJ, Aghajanian GK. LSD and the phenethylamine hallucinogen DOI are potent partial agonists at 5-HT2A receptors on interneurons in rat piriform cortex. J Pharmacol Exp Ther 1996; 278: 1373-82.

[14] Gewirtz JC, Marek GJ. Behavioral evidence for interactions between a hallucinogenic drug and group II metabotropic glutamate receptors. Neuropsychopharmacol 2000; 23: 569-76.

[15] Vollenweider FX. Advances and pathophysiological models of hallucinogenic drug actions in humans: a preamble to schizophrenia research. Pharmacopsychiatry 1998; 31: 92-103.

[16] Backstrom JR, Chang MS, Chu H, Niswender CM, Sanders-Bush E. Agonistdirected signaling of serotonin 5-HT2C receptors: differences between serotonin and lysergic acid diethylamide (LSD). Neuropsychopharmacol 1999; 21: 77S$81 \mathrm{~S}$.

[17] Bromo-Dragonfly \& the DEA Microgram Bulletin. Addiction Education Blog. http://www.cnsproductions.com/drugeducationblog/drug-information/24/ (Accessed March 16, 2011).

[18] Andreasen MF, Telving R, Birkler RI, Schumacher B, Johannsen M. A fatal poisoning involving Bromo-Dragonfly. Forensic Sci. Int. 2009; 183: 91-6.

[19] Wood DM, Looker J, Shaikh L, Button J, Puchnarewicz M, Davies S, Lidder S, Ramsey J, Holt D, Dargan PI. Delayed Onset of Seizures and Toxicity Associated with Recreational Use of Bromo-Dragonfly Clinical Toxicology, Guy's and St. Thomas' NHS Foundation Trust, London, UK. J Med Toxicol 2009; 5: 226-9.

[20] Erowid. http://www.erowid.org/ (Accessed on February 28, 2009).

[21] Cannabis Culture Forums. http://forums.cannabisculture.com/forums/ (Accessed February 28, 2009).

[22] Bluelight. http://www.bluelight.ru/vb/home.php (Accessed November 10, 2009). 
[23] Bromo-DragonFLY Trip: You Tube videos. http://www.neurosoup.com/bromodragonfly.htm. (Accessed November 5, 2009).

[24] Blue Crab. http://www.limit-point.com/BlueCrab/BlueCrab.html (Accessed November 5, 2009).

[25] Spotlight ${ }^{\mathrm{TM}}$ and Search $^{\mathrm{TM}}$. http://www.apple.com/macosx/what-is-macosx/ (Accessed November 5, 2009).

[26] Boolean Search ${ }^{\mathrm{TM}}$. http://www.limit-point.com/BooleanSearchServer/BSS.html (Accessed on November 5, 2009).

[27] Google Insights for Search analysis. www.google.com/insights/search (Accessed November 5, 2009).

[28] Drugs-forum. http://www.drugs-forum.com/index.php (Accessed February 8, 2010).

[29] eBay. http://www.ebay.com/ (Acessed November 18, 2009).

[30] Corazza O. Near-Death Experiences: exploring the mind-body connection. Routledge, London, NY 2008.

[31] Thorlacius K, Borna C, Personne M. Bromo-dragon fly--life-threatening drug. Can cause tissue necrosis as demonstrated by the first described case. (In Swedish only). Lakartidningen 2008; 105:1199-2000.

[32] Nyt stof har slået dansker ihjel. http://jp.dk/indland/aar/article1418250.ece （in Danish only). (Accessed October 30, 2009).

[33] Stolaroff MJ, Wells CW. Preliminary Results with New Psychoactive Agents 2CT-2 and 2C-T-7. Yearbook Ethnomed 1993; 99-117.

[34] Anonymous. "Bromo-Dragonfly" in Queensland, Australia. DEA Microgram Bulletin 2008; 41: 16.

[35] Corazza O, Schifano F. Ketamine use: a prospective study on the emergence of near-death states among a group of 50 ketamine recreational users. Subst Use Misuse 2010; 45: 916-924.

[36] BBC News. I nearly died from taking a $£ 5$ hit. http://news.bbc.co.uk/1/hi/england/surrey/7315020.stm (Accessed February 8, 2010) .

[37] Schifano F, Corazza O, Deluca P, Davey Z, the Psychonaut group. Psychoactive 
drug or mystical incense? Overview of the online available information on Spice products. International Journal of Culture and Mental Health 2009; 2: 137-44.

[38] Drogen-Forum. http://drogen-forum.us (Accessed March 17, 2011).

[39] Eurobarometer. Young people and drugs: Analytical report. http://ec.europa.eu/public_opinion/flash/fl_233_en.pdf. (Accessed November 17, 2009).

[40] Schifano F, Deluca P, the Psychonaut 2002 research group. Drugs on the web; the Psychonaut 2002 EU project preliminary results. Prog Neuro-Psychoph 2006; 30: 640-6.

[41] Corazza O, Davey Z, Deluca P, Demetrovics Z, Drummond C, Enea A, Moskalewicz J, Di Melchiorre G, Di Furia L, Farre' M, Flesland L, Scherbaum N, Siemann H, Skutle A, Torrens M, Pasinetti M, Pezzolesi C, Shapiro H, Sferrazza E, van der Kreeft P, and Schifano F. Le nuove potenzialità della prevenzione digitale in materia di nuove droghe: il ruolo del Recreational Drugs European Network. Dipendenze Patologiche/Addictive Behaviors, 43-46, 2010. 